\title{
Chapter 8 \\ The Impact and Challenges of Early \\ Mathematics Intervention in an Australian \\ Context
}

\author{
Ann Gervasoni
}

\begin{abstract}
This paper explores the design and longitudinal effect of an intervention approach for supporting children who are mathematically vulnerable: the Extending Mathematical Understanding (EMU) - Intervention approach. The progress over three years of Grade 1 children who participated in the intervention was analysed and compared with the progress of peers across four whole number domains. The findings show that participation in the EMU program was associated with increased confidence and accelerated learning that was maintained and extended in subsequent years for most children. Forty per cent of children were no longer vulnerable in the year following the intervention, and others were vulnerable in fewer domains. Comparative data for non-EMU participants highlights the wide distribution of mathematics knowledge across all children in each grade level. This explains why classroom teaching is so complex and highlights the challenges teachers face in providing inclusive learning environments that enable all students to thrive.
\end{abstract}

Keywords Mathematics difficulties - Mathematics intervention Inclusion - Whole number concepts $\cdot$ Mathematics assessment

\subsection{Introduction}

Leaders of school systems throughout the world voice concern about the phenomenon of children who experience difficulty with learning school mathematics and seek insight about how to overcome this situation. Ensuring that all children thrive mathematically is recognised as important for children's future citizenship and opportunities for work and further education, and ultimately for contributing to the economic and cultural prosperity of a society. The International Committee for Mathematics Education (ICME) actively supports research and development in this area. It commissioned a survey team to examine the state of the art with respect to

\footnotetext{
A. Gervasoni ( $\triangle)$

Monash University, Melbourne, Australia

e-mail: Ann.Gervasoni@monash.edu

(C) The Author(s) 2018

G. Kaiser et al. (eds.), Invited Lectures from the 13th International Congress

on Mathematical Education, ICME-13 Monographs,

https://doi.org/10.1007/978-3-319-72170-5_8
} 
the Assistance of students with mathematical learning difficulties-How can research support practice? (Scherer et al. 2016). The survey results highlight shifting paradigms in understanding mathematics learning difficulties, and found that approaches for identifying and assisting children are moving away from medical models towards more inclusive approaches.

In Australia, there is increased attention placed on the early identification of children who experience difficulty with learning school mathematics, and on providing these children with access to research-informed interventions to enable their learning. One approach is the Extending Mathematical Understanding (EMU) intervention program (Gervasoni 2004, 2015), developed by the author, and implemented in hundreds of Australian schools as part of a whole school approach to enabling mathematics learning for all (Fullen et al. 2006; Gervasoni et al. 2010). This approach and the outcomes are explored in this paper. It is anticipated that the insights gained from examining this intervention approach may contribute to the international discussion about the type of resources and strategies that can enable children to thrive mathematically. A particular focus is considering the longitudinal effect of the intervention approach for children who initially failed to thrive when learning school mathematics, and any implications for providing inclusive classroom environments that enable all children to learn mathematics successfully.

\subsection{Failure to Thrive When Learning Mathematics}

Currently there are contested views for explaining why children initially fail to thrive when learning school mathematics and for describing the phenomena of children who experience difficulty with learning mathematics. Gervasoni and Lindenskov (2011) argue from a social justice perspective, that these children have 'special rights' in mathematics education because historically they have not had access to high-quality mathematics programs and instruction. These students fall into two groups. The first group comprises those children who are visually or hearing impaired, or who have physical or intellectual impairments such as Down syndrome. The second group are those who underperform in mathematics due to their exclusion from quality mathematics learning and teaching environments that are necessary for them to thrive mathematically. Underperformance in mathematics is too often due to issues associated with equity and quality. Gervasoni and Lindenskov (2011) argue that many students in this first group have been directly excluded from opportunities and educational pathways in learning mathematics because mathematics was deemed an inappropriate field of study for them (e.g., Faragher et al. 2008; Feigenbaum 2000). The second group of students participate in mathematics classes, but they do not receive the quality of instruction or experience that enables them to thrive mathematically (Gervasoni and Sullivan 2007; Lindenskov and Weng 2008). These students are indirectly excluded from mathematics education. 
The perspective and principles underpinning the development and implementation of the EMU intervention approach are that all children have the right to access high quality mathematics education, at their local school, that enables them to thrive. This implies that all children can learn mathematics successfully given the necessary resources, environment, and teaching. However, it is important to acknowledge that providing high quality mathematics learning environments for all students is a struggle that may take some time to achieve. For example, in Tanzania, universal primary education has just become a reality for six-year-old children. First grade classes may include more than 100 students with access to few mathematics learning opportunities and teaching resources (Gelander et al. 2017). Even the most expert mathematics teacher may struggle to teach 100 children effectively in this environment. In contrast, Australia has the economic resources to provide six-year-old children with class sizes of 20-25 children and primary school teachers with at least 4-year degrees in teacher education. Australian children begin primary school at the start of the year in which they turn five, and have access to $15 \mathrm{~h}$ per week of pre-school education in the year prior to beginning school. However, even in this environment, not all Australian children thrive when learning mathematics at school and may be considered mathematically vulnerable. The term vulnerable is widely used in population studies (e.g., Hart et al. 2003), and refers to students whose environments include risk factors that can lead to poor developmental outcomes.

\subsection{The Extending Mathematical Understanding (EMU) Intervention Approach}

The EMU intervention approach is based on a social constructivist view of learning (Cobb et al. 1992) and the principle that all children can learn mathematics given access to the necessary resources, environment, and teaching. This view contrasts with many intervention approaches that consider mathematics learning difficulties from a medical or psychological paradigm rather than as a social construct. Magne (2003) extensive review of the literature on special educational needs in mathematics found that a medical model was adopted in the majority of studies surveyed; this positions mathematics difficulties as innate deficiencies as opposed to a socially, culturally, and politically constructed facet of identity and experience (Scherer et al. 2016). In the EMU approach, teachers focus on designing rich learning environments for all students that are responsive to differences in how children learn. The approach recognises that teachers need to be expert at understanding how individual children learn mathematics, and how they can advance this learning. This calls for a high level of professional knowledge. In Australia, primary classroom teachers are generalists and typically teach every curriculum area. This means that their initial teacher education rarely includes the depth of knowledge required to deal with the complexity of providing a truly inclusive mathematics classroom. 
Schools using the EMU approach first concentrate on enabling all classroom teachers to increase their mathematical pedagogical content knowledge (PCK), and their ability to design and implement inclusive learning environments. This involves providing professional learning opportunities to develop each teacher's knowledge and confidence. These schools also employ an EMU specialist teacher whose role is to provide three levels of support for vulnerable students and classroom teachers (Gervasoni 2015), including an EMU intervention program for the most vulnerable students in Grade 1. Level 1 EMU support provides classroom teachers with advice about how to best advance a child's mathematics learning, and this is supplemented by an individual learning plan that outlines the learning goals and experiences that may boost a particular child's learning. Level 2 support provides this same advice plus in-classroom support (e.g., peer teaching, coaching, small group teaching) for children during mathematics lessons. Level 3 includes a small group EMU intervention program for prioritised students. This daily withdrawal program is coordinated with the classroom mathematics program. EMU specialist teachers complete a 36-hour course (at Masters level) that focuses on assessment of children's knowledge and dispositions, mathematical pedagogical content knowledge, and instructional design that maximises mathematics learning for all. This professional learning program recognises that specialist mathematics teaching knowledge is one important factor in enabling all students to thrive mathematically (Hill et al. 2005). Specialists also complete at least $25 \mathrm{~h}$ of field-based learning associated with teaching the EMU intervention program, and a program of professional reading prior to being accredited. Ongoing accreditation requires that EMU specialists engage in two days of ongoing professional learning each year.

Level 3 EMU support provides Grade 1 children who are mathematically vulnerable with an intervention program that aims to accelerate their learning and increase their confidence, so that ultimately they can thrive in the regular classroom environment. The intervention is also possible for older students, depending on the available resources in a school. During this intervention, groups of three children (6-year-olds) participate in 30-min lessons 5 days per week for a total of 10 20 weeks (i.e., 50-100 lessons), depending on their progress. The lessons are designed and customised for each student because of the diverse range of knowledge and difficulties noted amongst those who are mathematically vulnerable (see Table 8.1). Gervasoni and Sullivan (2007) found that it was rare to find two students with the same difficulties. The theoretical underpinnings of the EMU intervention program, the teaching approach, and lesson structure are described in detail in Gervasoni (2004), and also in the accompanying book for specialist teachers (Gervasoni 2015). In brief, each 30-min lesson focuses on: whole number learning with an introduction to build connections with recent learning (2-min); activities to develop children's understanding of quantities and numerosity, including place value and counting knowledge(8-min); mathematical investigations and open tasks involving the four operations, with an emphasis on the development of heuristic arithmetic and reasoning strategies (15-min); reflection on learning (5-min); and assignment of a daily home task (usually a mathematics game) to involve parents in the children's learning. Specialist teachers are encouraged to be responsive to what 


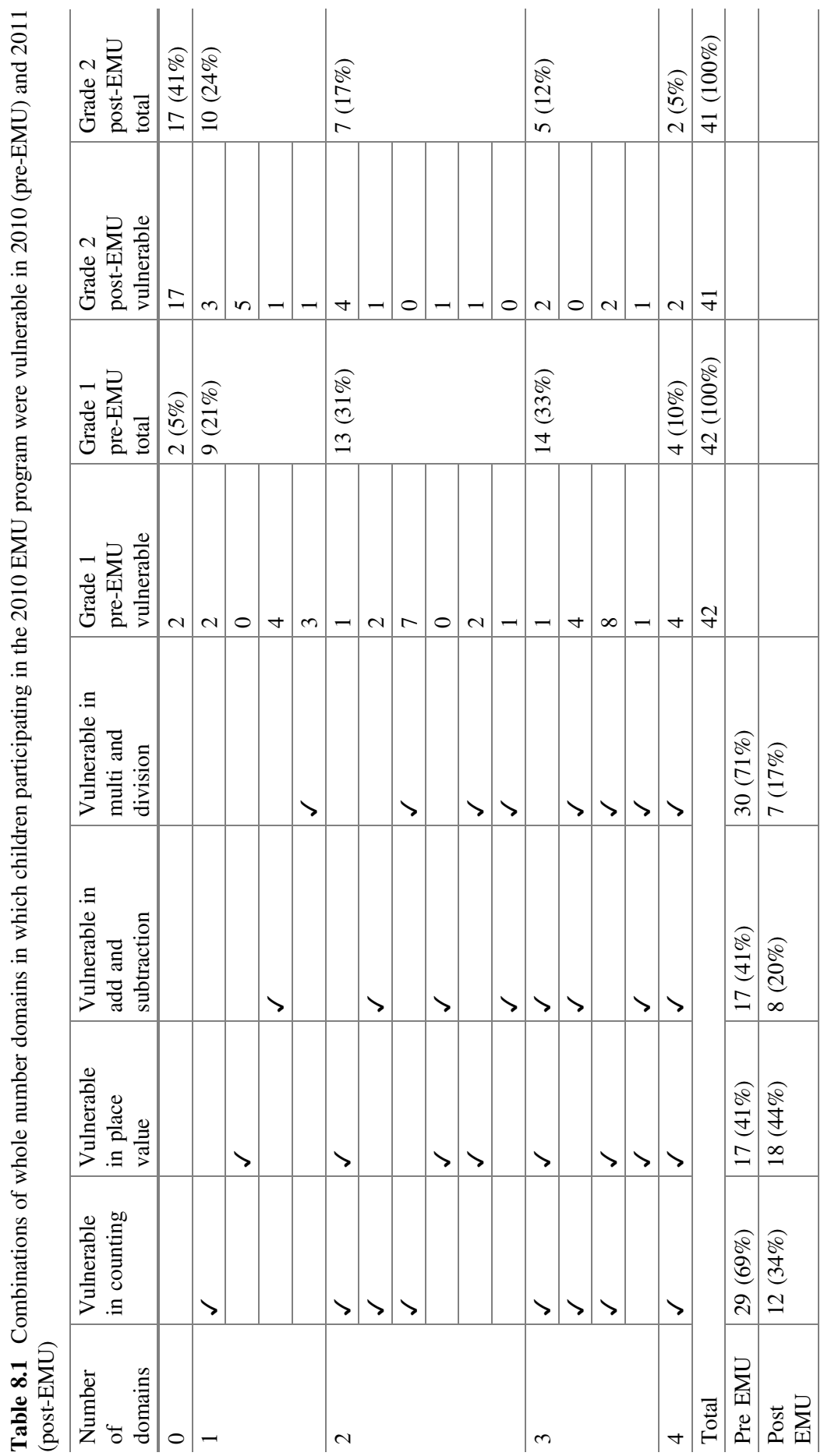


they learn about each student during each lesson. The pedagogical approach encourages children to use concrete models to assist with their construction of new knowledge, and teachers prompt children to simulate, imagine, and describe solutions derived from using these concrete models. Children are also expected, and supported, to explain their thinking and strategies, and to develop confidence and positive mind-sets. The course for EMU specialist teachers emphasises these pedagogical approaches, and detailed explanations and illustrative examples are provided in the 220 page Extending Mathematical Understanding: Intervention book for teachers (Gervasoni 2015).

\subsection{Using Growth Point Profiles to Identify Children Who May Benefit from an Intervention Program}

While the aim of inclusive mathematics education is for each child to thrive with their learning in their classroom, it is also necessary to identify those children who are not thriving and to change their experience of learning. Sometimes a more intensive learning experience than what is available in a regular classroom is helpful in the short term. This is the intent of the EMU intervention program.

The EMU approach begins with the proposition that the classroom and specialist teachers need to deeply understand each child's current mathematical understanding and strategies. This process is facilitated through reference to a framework of mathematics growth points that help teachers recognise children's current understanding in four whole number domains, and guide their teaching. The growth point framework in the EMU approach was developed during the Early Numeracy Research Project (Clarke et al. 2002) and further refined in 2013 (Gervasoni et al. 2011). The processes for validating the growth points, the associated assessment interview items, and the comparative achievement of students are described in full in Clarke et al. (2002) and have been reported widely (e.g., Clarke 2001, 2013). From a research and evaluation perspective, the framework of growth points also enables children's learning progress to be measured. The growth points do not represent an assessment score, but rather describe a child's current knowledge in reference to the set of research-informed progressions in children's developing knowledge. This is a common approach in Australia (Bobis et al. 2005). The idea is that the growth points guide teachers about how they might respond to a child's current knowledge, and then provide the resources and teaching to extend their learning.

School communities using the EMU approach organise for classroom teachers to assess all children in their class using the Mathematics Assessment Interview (Gervasoni 2011). This one-on-one assessment requires the teacher to sit with each child, and to observe and probe their thinking and strategies for solving mathematics tasks, until they have a deep understanding of the extent of the child's current whole number knowledge. Based on children's strategies and responses, the 
detailed assessment script leads children through different tasks in nine whole number, measurement, and geometry domains, just like a choose your own adventure story. Following the assessment, the teacher analyses each child's responses to determine their growth point profile, and identifies whether any children are mathematically vulnerable. In the EMU intervention context, the four whole number domains (Counting, Place Value, Addition and Subtraction Strategies, and Multiplication and Division Strategies) have been shown to be the most reliable for identifying children who were mathematically vulnerable. In contrast, children's performance in the measurement and geometry domains was much less predictable (Gervasoni 2004). This emphasis on the whole number domains for identifying and prioritising children who may benefit from an EMU intervention program does not diminish the importance of children's measurement and geometry learning. Rather, it has been found that children have typically learnt measurement and geometry knowledge successfully in the classroom environment.

To illustrate the nature of the growth points (see Clarke et al. 2002; Gervasoni 2015 for detailed descriptions) and the wide distribution of knowledge in any grade level, Fig. 8.1 shows the 2016 Multiplication and Division Strategies distribution of growth points for all 21,884 primary students in a region of the New South Wales.

The wide distribution of growth points in every grade level was evident also in each of the other three whole number domains. For each grade level, it is clear that there is a group of students who are failing to thrive in comparison to their peers. It is also clear that responding to this wide distribution of knowledge is highly complex for teachers, and requires the classroom teacher to be highly skilled in customising mathematics lessons and teaching. An inference from these data is that children on the lowest growth points in a class may be marginalised, with the teacher struggling to provide the resources necessary to enable all to learn.

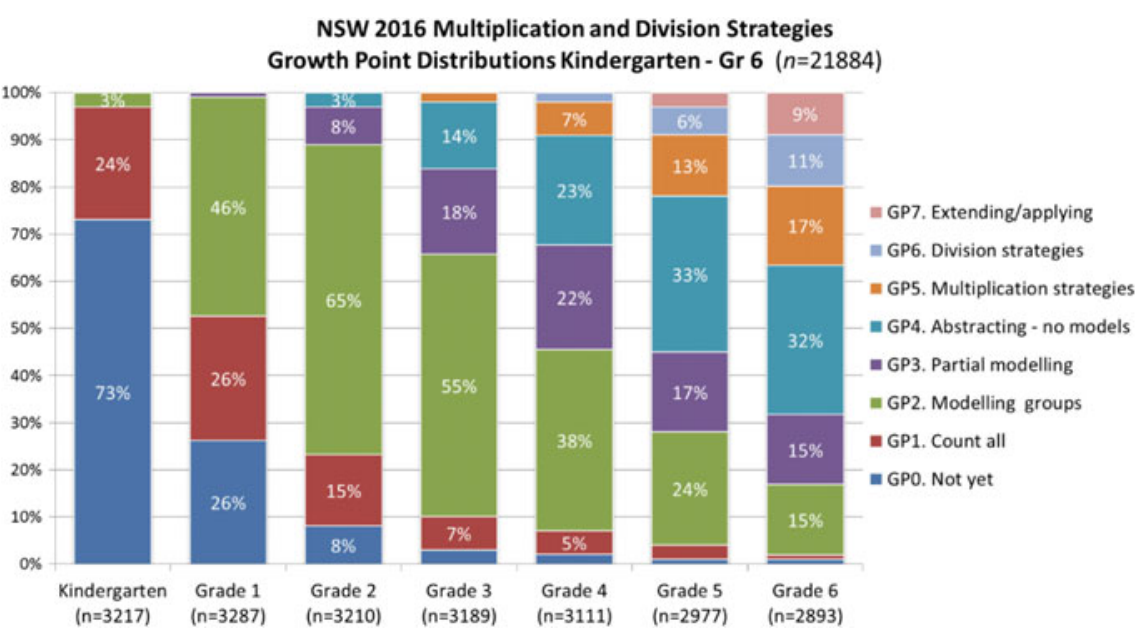

Fig. 8.1 Multiplication and Division Strategies growth point distributions for children in Kindergarten to Grade 6 in 2016 
The EMU approach uses children's growth point profiles in the four whole number domains to prioritise children for Level 3 EMU intervention. For example, in the domain of Multiplication and Division Strategies, Grade 1 children who do not yet use count-all strategies (growth point one) to solve multiplicative problems are considered mathematically vulnerable in this domain, and they qualify for specialist EMU intervention support (Gervasoni 2004). This is because their current inability to use count-all strategies for simple multiplicative tasks excludes them from engaging with typical Grade 1 learning activities.

\subsection{Progress of Students Who Participated in an EMU Intervention Program}

Several studies have investigated the impact of the EMU intervention program (e.g., Clarke et al. 2002; Gervasoni 2004). During the Bridging the Numeracy Gap in Low SES and Aboriginal Communities Pilot Project (BTNG) (Gervasoni et al. 2011, 2012), the longitudinal progress of six-year-old students who participated in an EMU intervention program in 2010 was measured over three years using the ENRP growth point framework. The participants in the BTNG research all belonged to socially disadvantaged communities, as classified by the Australian Government, and formed two groups. The first group was the 42 Grade 1 children who, in 2010, took part in an EMU intervention program for 10-20 weeks. The second comparison group comprised all 2545 Grade 1 (6-year-old) to Grade 4 (9 year-old) children who attended the schools involved in the study during 2010 2011. All these schools employed an EMU Specialist Teacher who was able to provide support for children who were mathematically vulnerable, and all children in these schools were assessed by their classroom teachers using the Mathematics Assessment Interview (MAI). Following this assessment, their associated whole number growth points in 2010 and 2011 were used to provide a comparative measure of mathematics growth for all children in the study. Children's growth point profiles, and any vulnerability in the four number domains, were used to prioritise Grade 1 children for participation in the EMU intervention program, according to the protocol identified by Gervasoni (2004), with those classified as Priority 1 (most vulnerable) being the first to be offered the intervention. None of the schools had the financial resources to offer intervention programs to all children who were mathematically vulnerable.

Of interest for the BTNG longitudinal study was whether the EMU intervention program accelerated children's mathematics learning and how their learning progressed over three years. These students from the states of Victoria and Western Australia were all the most mathematically vulnerable students in their class, based on their MAI assessment and growth point profiles (Gervasoni 2004). Table 8.1 shows the number of whole number domains and the combination of domains for which these 42 children were vulnerable at two time points: (1) at the beginning of 
Fig. 8.2 The percentage of EMU participants who were vulnerable in $0,1,2,3$ or 4 whole number domains in 2010 and 2011

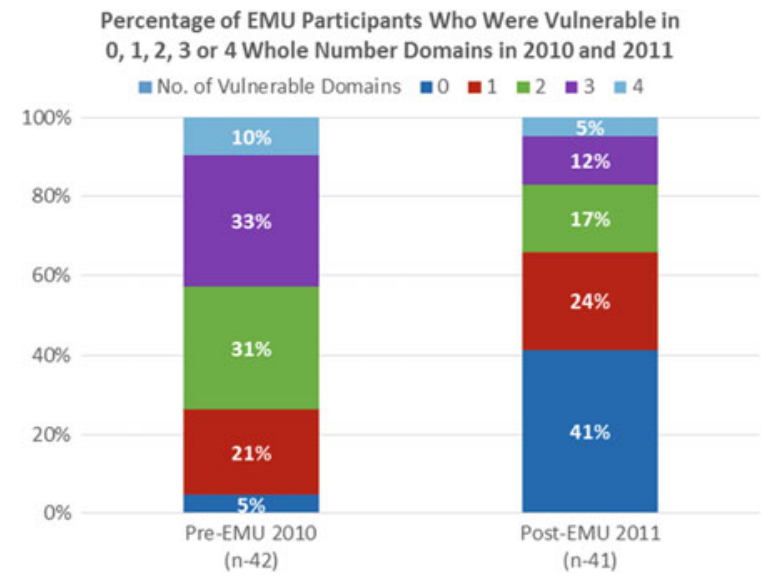

Grade 1 and before they began the EMU intervention program; and (2) 12 months later, at the beginning of Grade 2 and after these children had completed both the EMU Program in the previous year and the long summer holiday. Figure 8.2 shows the decrease in the number of domains for which children were vulnerable after the 2010 EMU Program. It is important to note that the growth points used for identifying children as vulnerable in Grade 2 (2011) were increased by one growth point in each domain to account for median growth across 12 months. For example, children beginning Grade 1 were identified as vulnerable in Counting if they did not reach Growth Point 2. At the beginning of Grade 2, children were identified as vulnerable in Counting if they did not reach Growth Point 3.

The data suggest that these children were a diverse group. Pre-EMU, some were vulnerable in only one domain $(21 \%)$, some in two (31\%) or three domains $(33 \%)$, but only four students $(10 \%)$ were vulnerable in all four domains. This is consistent with the findings of Clarke et al. (2002) during the Early Numeracy Research Project. Further, the combinations of domains for which the students were vulnerable prior to participation in the EMU intervention program varied. Clearly, there was no one pattern to describe students who were mathematically vulnerable. This highlights the complexity of teaching, and the need for teachers to be expert at understanding children's current knowledge and in designing learning environments that are personalised to enable all children to learn.

From an evaluation perspective, the EMU program aims for no children to be mathematically vulnerable at the end of the program or, as a minimum, for children to be vulnerable in fewer domains. To measure the effect of the EMU program for decreasing the domains for which children are mathematically vulnerable, children's EMU growth point data were collected by the new classroom teacher at the beginning of Grade 2, that is, after the long summer holidays. The data shown in Table 8.1 and Fig. 8.2 show that in 2011, after experiencing the EMU Program in 2010, the vast majority of students were vulnerable in fewer domains, and almost half were no longer vulnerable at all. It is important to note that the growth points 
used to identify a student as vulnerable in 2011 were one growth point higher in each domain compared with those used in 2010 and before the EMU Program. This increase adjusts for the typical growth in knowledge across one year of schooling (Clarke et al. 2002). The results suggest that most of the children were in a stronger position to thrive mathematically in 2011 compared with the previous year. However, $17 \%$ of children remained vulnerable in 3 or 4 domains. The challenge remained for their 2011 Grade 2 classroom teacher to create the learning experiences that would enable these children to thrive.

A paired-samples t-test was conducted to determine whether the change in the number of domains for which children were vulnerable before and after the intervention was significant. There was a statistically significant decrease in the number of domains for which children were vulnerable in 2010 before EMU ( $M=2.20$, $\mathrm{SD}=1.05)$ and in 2011 after $\mathrm{EMU}(\mathrm{M}=1.15, \mathrm{SD}=1.24), \mathrm{t}(40)=6.13, p<.001$ (two-tailed). The mean decrease in vulnerable domains was 1.05 with a $95 \%$ confidence interval ranging from 0.703 to 1.394 . The eta squared statistic (.48) indicated a large effect size. While the study design does not enable the claim to be made that the EMU intervention program was the sole cause of this decrease in vulnerability, the intervention program was likely to be a contributing factor.

\subsection{Longitudinal Impact on Mathematics Knowledge and Growth Points Over Three Years}

The data presented in the previous section highlight that participation in the EMU program was associated, typically, with an acceleration in some children's whole number learning and a decrease in the number of domains in which they were vulnerable. However, it is also important to determine whether this learning was maintained and extended in the following years. To evaluate the longitudinal progress of students who participated in a Grade 1 EMU intervention program only in 2010 (but not in subsequent years), the EMU group's growth point distributions in 2010-2013 for each domain were calculated and compared with the progress of all students in the entire cohort (including EMU students). Figure 8.3 shows the growth point distributions for the two groups for the Multiplication and Division Strategies domain from 2010 to 2013 . Note that due to the BTNG project ending in 2011, longitudinal data for students in the comparison 2012 Grade 3 cohort and the 2013 Grade 4 cohort were unavailable, so available 2011 data for all Grade 3 and Grade 4 students in the same schools were used to illustrate the distributions that might be expected of the 2012 Grade 3 and 2013 Grade 4 cohorts. An asterisk indicates this use of 2011 Grade 3 and Grade 4 data in Figs. 8.3, 8.4, 8.5 and 8.6. Only growth point data for children in the EMU intervention group were available for collection in 2012 and 2013 due to a limited extension of the BTNG project to enable these children's longitudinal progress to be measured. 


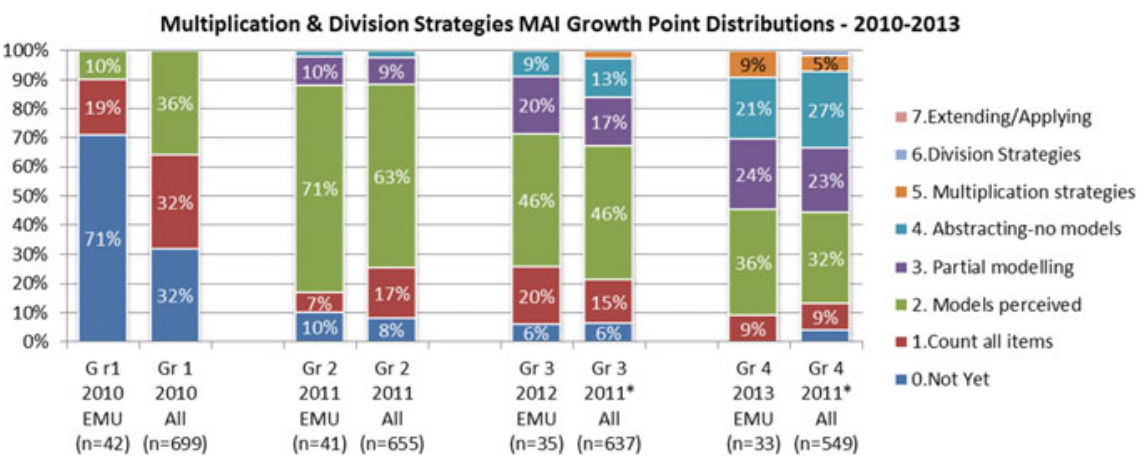

Fig. 8.3 2010-2013 multiplication and division growth point distributions (beginning of the year) for the 2010 EMU group, and comparison data for all Grade 1-Grade 4 students

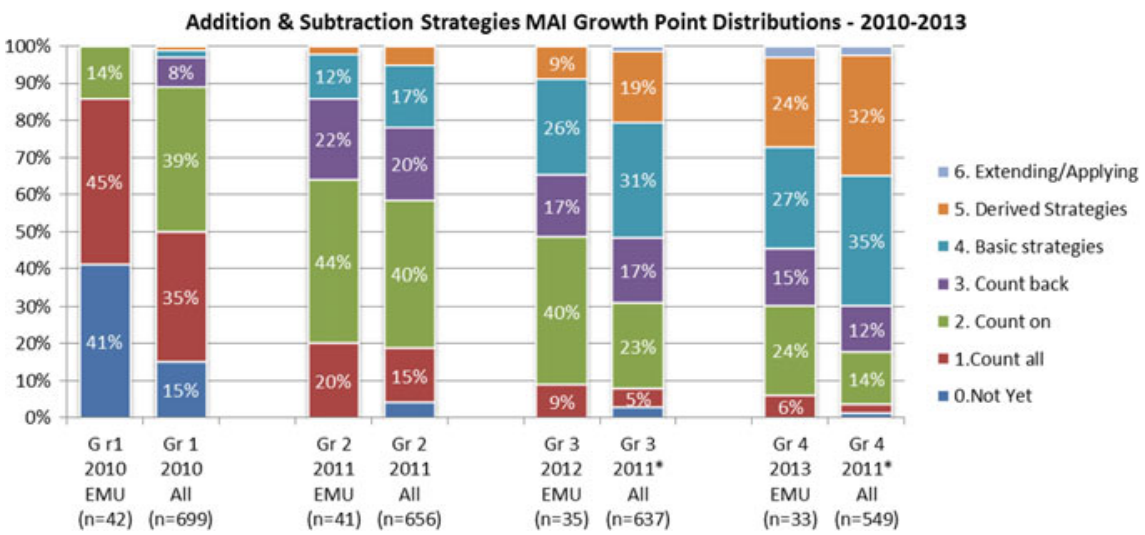

Fig. 8.4 2010-2013 addition and subtraction growth point distributions (beginning of the year) for the 2010 EMU group and comparison data (2010-2011) for all Grade 1-Grade 4 students

Figure 8.3 shows that the spread of Multiplication and Division Strategies growth points for the 2010 EMU group was substantially different to their peers, with $71 \%$ of the EMU group on Growth Point 0 (GP0) compared with only $32 \%$ of their peers. However, the EMU group made substantial growth by 2011. It is noticeable how similar the spread of growth points are in 2011 for both the EMU group and their peers $(A l l)$ in Grade 2. This finding was also apparent for the other whole number domains (see Figs. 8.4, 8.5 and 8.6). These data suggest that one effect of the EMU Program in 2010 was an acceleration of whole number learning to the extent that the EMU group's growth point distribution at the beginning of 2011 (Grade 2) mirrored that of their peers. Nevertheless, while some EMU students progressed two or three growth points in each domain across 2010-2011, some remained vulnerable when they reached Grade 2 and remained on the lowest 


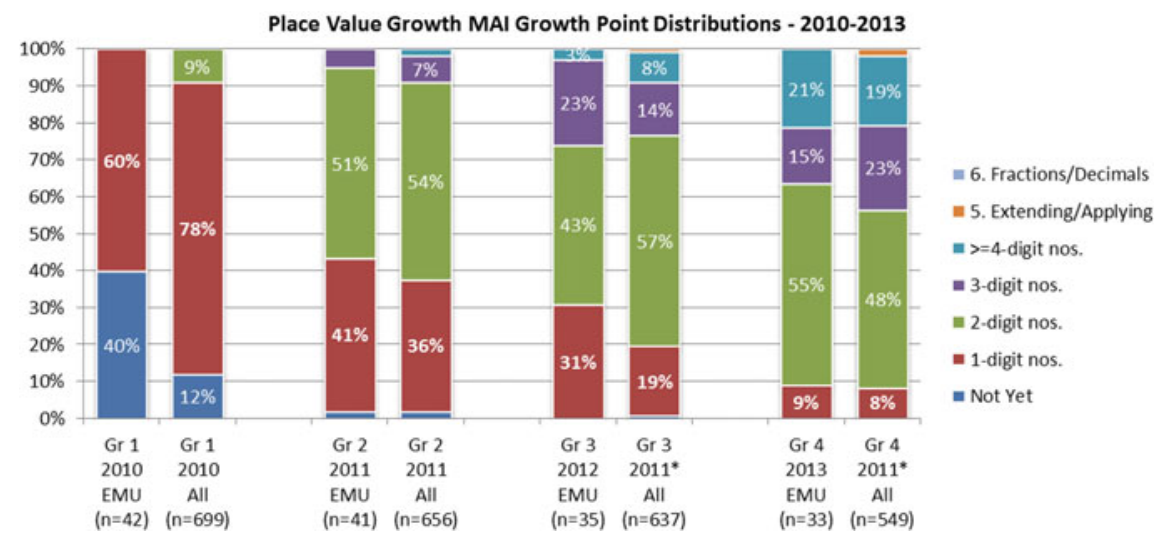

Fig. 8.5 2010-2013 place value growth point distributions (beginning of the year) for the 2010 EMU group and comparison data (2010-2011) for all Grade 1-Grade 4 students

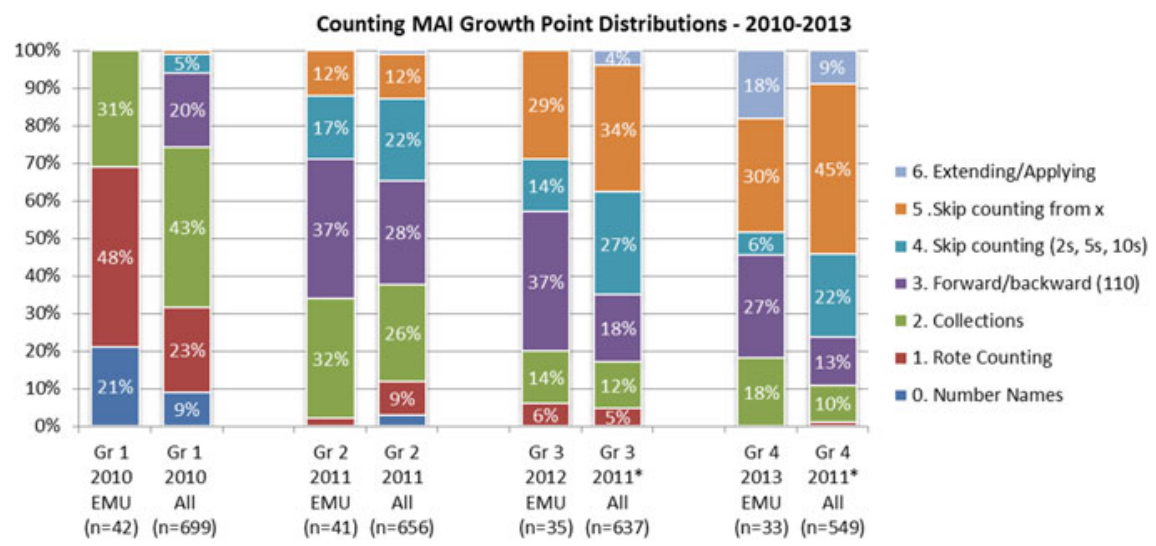

Fig. 8.6 2010-2013 counting growth point distributions (beginning of the year) for the 2010 EMU group and comparison data (2010-2011) for all Grade 1-Grade 4 students

growth points (GP0 and GP1). Such vulnerable students, including those who do not participate in the Grade 1 intervention program, are of concern and may benefit from additional assistance throughout Grade 2.

Overall, it is clear from the data presented in Figs. 8.3, 8.4, 8.5 and 8.6 that the majority of students participating in the EMU intervention program made accelerated progress in each domain by the beginning of Grade 2 (2011). It is also important to consider whether their progress continued or faded in 2011-2013 when they no longer had the opportunity afforded by an intervention program. A comparison of the Grade 2-Grade 4 Multiplication and Division growth point distributions (Fig. 8.3) for the 2010 EMU group suggests that their learning was maintained during this period, but that the rate of progress for many students was 
less in the following years when they no longer received additional support from a specialist teacher. Transition from one growth point to the next growth point in the framework represents a significant step in a student's development that may take 12 months to achieve, as opposed to smaller steps in learning that are noticeable day by day (Clarke et al. 2002). Figure 8.3 shows that, typically, the children in the highest quartile of the EMU cohort distribution (on GP3 and GP4) at the beginning of Grade 2 (2011) progressed one additional growth point from 2012 to 2013 in the Multiplication and Division Strategies domain, but EMU students in the lowest quartile distribution (on GP0 and GP1) of the cohort distribution made less progress, on average. Encouragingly, the rate of progress of students in the 2010 EMU group from 2011 to 2013 was consistent with the progress of their peers $(A l l)$. Children on the lowest growth points struggled to make progress in 2011 and may not have benefitted greatly from their classroom experiences in Grade 2.

Figure 8.4 shows children's progress in the Addition and Subtraction Strategies domain. The EMU group made strong progress from 2010 to 2011 after the period of the intervention program but, although their learning was maintained in subsequent years, the rate of progress reduced.

It is of interest to examine the progress of both the EMU Group and their peers (All) from Grade 2 to Grade 3 (2011-2012). On average, comparison students in the upper $50 \%$ of the Grade 2 distribution were likely to progress at least one growth point by Grade 3 (e.g., GP3-GP4 or GP4-GP5), but the learning for most EMU students in the bottom half of the Grade 2 distribution has stagnated by Grade 3 on GP1 and GP2. That is, 64\% of the EMU students were on GP1 or GP2 at the beginning of Grade 2 and 49\% were still on GP1 or GP2 at the beginning of Grade 3. It appears that being able to move from using a count-on strategy for addition (GP2) to a count-back strategy for subtraction (GP3) is a difficult progression for many students.

In the Place Value domain, mean growth for children is just less than one growth point per year (Clarke et al. 2002). Examining the data in Fig. 8.5 for Grade 2, Grade 3 and Grade 4 children in both the EMU and comparison groups shows that the median was GP2 (understanding 2-digit numbers) in all these distributions. From year to year, this was less growth than might be expected and suggests that many children's place value knowledge was stagnating from Grade 2 through to Grade 4. Further, comparisons between the growth from Grade 2 to Grade 3 for both the EMU group and their peers ( $A l l$ ) suggest that, on average, students beginning Grade 2 on GP1 or GP2 (success with tasks involving 1-digit and 2-digit numbers respectively), were highly likely to remain on these growth points one year later. These findings suggest that learning opportunities in Grade 2 and Grade 3 classrooms were insufficient for all students in Place Value. This is an issue for school systems to investigate.

Inspection of the 2010 EMU group's progress in the Counting domain (Fig. 8.6) suggests that, on average, learning was accelerated across Grade 1 for EMU students during the intervention period. There was substantial change in the proportion of EMU students in the lowest two growth points (GP0 and GP1) from Grade 1 to 
Grade 2. Further, there were proportionally fewer children in the EMU group on these growth points in Grade 2 than among the All students group.

The data in Fig. 8.6 suggest that progress for some EMU students was likely to stagnate across Grade 2 and Grade 3, particularly if children began the year on Growth Point 2 (can count at least 20 objects) or Growth Point 3 (can count by ones past 109 and back from 24). In stark contrast, the EMU children who began on Growth Point 2 at the beginning of Grade 1, on average, were likely to progress to at least Growth Point 3 one year later. This suggests that instruction in Grade 2 and Grade 3 may not have been sufficiently focused on supporting students to learn to skip count (GP4 and GP5). Skip counting, or the teaching of skip counting, appears to present a barrier that prevents some students from progressing beyond GP3.

\subsection{Impact of EMU Intervention on Children's Confidence for Learning Mathematics}

Another goal of the EMU intervention program is to develop children's positive dispositions for learning mathematics. However, this aspect of children's learning was not investigated during the BTNG project described earlier. To gain some insight on any impact of the EMU intervention program in this regard, $127 \mathrm{EMU}$ specialist teachers in New South Wales who completed their course in 2016 were surveyed. They were asked, "What key changes have you observed in your students as a result of their participation in the EMU program?" Seventy-nine of the teachers $(62 \%)$ noted changes in children's confidence. Several responses that illustrate the impact of the EMU intervention program on children's confidence include the following:

The increase in the students' confidence has been the biggest change. The students are more willing to participate in classroom mathematics.

Confidence and engagement/enjoyment in maths has been a huge change - these kids are now approaching maths with a positive mindset and (as reported back from the classroom teachers following the course) these students are now much more likely to 'have a go' in their classrooms, persevere with their learning if they find it difficult, and look for different ways/strategies to solve a problem.

I could not believe the speed with which they showed improvement. After 2 weeks they were more confident in sharing their strategies and ideas and it carried over into the classroom too. Teachers have reported that the students in EMU were more confident in Maths and used a wider variety of strategies than other students. The students taught their classmates some of their activities and became 'the experts'!

The confidence that my students now demonstrate is fantastic. They are so much more engaged in numeracy in their classrooms and love to contribute ideas and explain their thinking.

Another strong theme in the responses was the positive change in children's engagement in classroom mathematics learning. This is also evident in the responses above. These data suggest that the EMU intervention program, as 
perceived by the specialist intervention teachers, had a positive effect on children's dispositions for learning mathematics, as well as on their mathematics knowledge and problem solving. Further, the data suggest that this increased confidence may have transferred to children's experience of learning mathematics in their classrooms.

\subsection{Issues Related to Effective Intervention Approaches}

The data presented earlier demonstrate that the mathematics learning of most children who participated in the EMU intervention program increased across the year, and that this learning was mostly maintained and extended in the subsequent three years. Further, most children gained in confidence and had more positive attitudes to learning mathematics, as noted by their classroom teachers. Thus, the majority of children were more strongly positioned to thrive mathematically in their classroom environment following participation in an EMU intervention program. This impact was further demonstrated by many EMU participants no longer being mathematically vulnerable or being vulnerable in fewer domains, with associated increased mathematics knowledge and confidence to bring to the classroom learning environment. Thus, the EMU program is likely to have assisted children to benefit more fully from their classroom mathematics learning in subsequent years. However, some children remained vulnerable. It is possible that these children may benefit from ongoing support from a specialist teacher who can advise the classroom teacher about the type of experiences and teaching adjustments that can enable their learning. Indeed, a specialist teacher can play an important role across the school in providing professional learning opportunities and advice for classroom teachers as they work towards providing a more effective and inclusive environment for mathematics learning.

The longitudinal data that described the progress of EMU children, alongside the whole cohort of students for comparison, clearly demonstrated that there were points when many children's mathematics learning stalled for 12 months or longer. This finding suggests that the classroom teachers may have needed further support to improve their pedagogical content knowledge to respond productively to all children's current mathematical understanding, and to provide experiences that enabled growth for all. Inclusive mathematics education calls upon teachers to provide learning experiences and teaching based on what children currently know, within the framework of a curriculum document. The wide distribution of knowledge in any one classroom across multiple mathematical domains, as demonstrated in Figs. 8.3, 8.4, 8.5 and 8.6, highlights the complex situation that teachers face when designing inclusive mathematics learning environments. It may be that the teaching approaches used by the EMU specialist teachers in the intervention program may be beneficial for classroom environments also. This would include: providing tasks that can be differentiated to enable children to engage in different ways and levels; adopting teaching strategies that enable children to use concrete 
models to assist with problem solving in new topic areas; encouraging children to simulate and describe their actions with concrete models; and providing opportunities for children to discuss their mathematical conjectures. Identifying effective teaching approaches that respond to the wide variation in children's mathematical knowledge is an important topic for ongoing research and development.

The increased learning for children in the EMU intervention group was noticeable when comparing the growth point spread for EMU students and their peers when the children reached Grade 2. Indeed, by Grade 2 (2011), and again in Grade 3 (2012) and Grade 4 (2013), the growth point distributions of both groups were very similar, in contrast to the marked differences observed between the two groups in 2010. However, an important issue apparent in the EMU group's Grade 2, Grade 3, and Grade 4 growth point distributions was that learning for some students seemed to stall across these grades; generally students in the top quartile of the growth point distribution were most likely to progress. This finding suggests that classroom mathematics teaching for Grade 2-Grade 4 students may not be sufficiently differentiated to enable all students to thrive. The analyses also suggest that not all Grade 1 children who participated in an EMU intervention program experienced accelerated learning in all whole number domains. Longitudinally, one-quarter of the EMU group reached the highest growth points found in the 2011, 2012 and 2013 distributions for All students, while a proportion of the EMU group remained mathematically vulnerable in subsequent years. These EMU children progressed, but remained mathematically vulnerable as the curriculum demands increased. Further insights are needed about effective strategies to assist these students.

Participation in the EMU intervention program was associated with most Grade 1 children progressing their whole number learning beyond the one growth point anticipated in each domain across one school year. This was true even for the children who began on the lowest growth points. It was also apparent that their learning was maintained over subsequent years, although some students' learning progression stagnated. This stagnation in learning was noted also for students in the All students comparison cohort. Profitable areas for further research and development are: (a) seeking insight into why some students make less progress during an intervention program than others, and (b) designing classroom instruction for Grade 2-Grade 4 students that is more inclusive and better enables mathematics learning for all. It may be beneficial for an EMU specialist teacher to be more available to advise Grade 2-Grade 4 teachers about how to refine curriculum and customise teaching to enable all to learn. It is also likely that some students may benefit from more specialised mathematics teaching beyond Grade 1, and also that classroom teaching in Grade 2-Grade 4 may need to be more responsive to students' individual learning needs. The importance of teachers' mathematical knowledge for teaching has been increasingly recognised as a key to achieving desired learning outcomes for all students (Hill et al. 2005). 


\subsection{Conclusion}

The research and experiences presented in this chapter suggest that participation in a Grade 1 EMU intervention program was associated with accelerated mathematics learning for most students and that this learning was generally maintained and extended in the following three years. It appears that the EMU program also results in children gaining confidence as learners of mathematics. A review of the Maths Recovery Program (Smith et al. 2013) concluded that mathematics intervention programs must be coordinated with, rather than isolated from, the classroom mathematics program. This conclusion is supported by Clements et al. (2013) who further claim that interventions in the early years need to be scaled-up in subsequent years to be most effective for students. The longitudinal data presented in this chapter highlight that although most EMU intervention participants' learning was maintained in subsequent years, some students stalled in their learning at various points in the three years after the EMU Program concluded. This supports the findings of Smith et al. (2013) and Clements et al. (2013) that interventions need to be co-ordinated with classroom programs and scaled-up in subsequent years for their impact to be extended beyond the intervention period. Following an intervention program, if children continue to experience the same conditions under which they were marginalised and excluded from learning mathematics in the first place, then their learning may again be disrupted. It is possible that specialist intervention teachers have a role to play in scaling-up intervention in subsequent years through supporting classroom teachers to provide an inclusive mathematics learning environment in which all students can thrive.

Acknowledgements The research reported in this paper was funded by the Australian Government as part of the Bridging the Numeracy Gap in Low SES and Indigenous Communities Project. The author acknowledges gratefully the contribution of the research team and all participating teachers, parents, students, and school communities.

\section{References}

Australian Curriculum, Assessment and Reporting Authority [ACARA]. (2012). Australian curriculum: Mathematics. Sydney: ACARA. Retrieved from http://www.australiancurriculum. edu.au/mathematics/curriculum/f-10?layout=1.

Bobis, J., Clarke, B., Clarke, D., Thomas, G., Wright, R., Young-Loveridge, J., et al. (2005). Supporting teachers in the development of young children's mathematical thinking: Three large scale cases. Mathematics Education Research Journal, 16(3), 27-57.

Clarke, D. (2001). Understanding, assessing and developing young children's mathematical thinking: Research as powerful tool for professional growth. In J. Bobis, B. Perry, \& M. Mitchelmore (Eds.), Numeracy and beyond: Proceedings of the 24th Annual Conference of the Mathematics Education Research Group of Australasia (Vol. 1, pp. 9-26). Sydney: MERGA.

Clarke, D. (2013). Understanding, assessing and developing children's mathematical thinking: Task-based interviews as powerful tools for teacher professional learning. In A. M. Lindmeier $\&$ A. Heinze (Eds.), Proceedings of the 37th Conference of the International Group for the 
Psychology of Mathematics Education, Mathematics Learning Across the Life Span (Vol. 1, pp. 17-30). Kiel, Germany: PME.

Clarke, D., Cheeseman, J., Gervasoni, A., Gronn, D., Horne, M., McDonough, A., et al. (2002). ENRP final report. Melbourne: ACU.

Clements, D., Sarama, D., Wolfe, C., \& Spitler, M. (2013). Longitudinal evaluation of a scale-up model for teaching mathematics with trajectories and technologies: Persistence of effects in the third year. American Educational Research Journal, 50(4), 812-850.

Cobb, P., Yackel, E., \& Wood, T. (1992). A constructivist alternative to the representational view of mind in mathematics education. Journal for Research in Mathematics Education, 23(10), 2 33.

Faragher, R., Brady, J., Clarke, B., \& Gervasoni, A. (2008). Children with down syndrome learning mathematics: Can they do it? Yes they can! Australian Primary Mathematics Classroom, 13(4), 10-15.

Feigenbaum, R. (2000). Algebra for students with learning disabilities. The Mathematics Teacher, 93(4), 270-276.

Fullan, M., Hill, P., \& Crévola, C. (2006). Breakthrough. Thousand Oaks: Corwin Press.

Gelander, G. P., Rawle, G., Karki, S., \& Ruddle, N. (2017). EQUIP-Tanzania impact evaluation midline issue note 1: The changing context for teacher in-service training-Reflections on equip-Tanzania's experience. Tanzania: Oxford Policy Management. Retrieved from http:// microdata.worldbank.org/index.php/catalog/2838.

Gervasoni, A. (2004). Exploring an intervention strategy for six and seven year old children who are vulnerable in learning school mathematics Unpublished doctoral dissertation. Bundoora: La Trobe University.

Gervasoni, A. (2011). Exploring the whole number knowledge of children in grade 1 to grade 4: Insights and implications. In T. Dooley, D. Corcoran, \& M. Ryan (Eds), Mathematics Teaching Matters: Proceedings of the 4th Conference on Research in Mathematics Education (pp. 168 178). Dublin: St Patrick's College Drumcondra.

Gervasoni, A. (2015). Extending mathematical understanding: Intervention. Ballarat, Australia: BHS Publishing.

Gervasoni, A., \& Lindenskov, L. (2011). Students with 'special rights' for mathematics education. In B. Atweh, M. Graven, W. Secada, \& P. Valero (Eds.), Mapping equity and quality in mathematics education (pp. 307-323). The Netherlands: Springer.

Gervasoni, A., \& Sullivan, P. (2007). Assessing and teaching children who have difficulty learning arithmetic. Educational \& Child Psychology, 24(2), 40-53.

Gervasoni, A., Parish, L., Hadden, T., Livesey, C., Bevan, K., Croswell, M., et al. (2012). The progress of grade 1 students who participated in an extending mathematical understanding intervention program. In J. Dindyal, L. P. Cheng, \& S. F. Ng (Eds.), Mathematics Education: Expanding Horizons: Proceedings of the 35th Annual Conference of the Mathematics Education Research Group of Australasia (pp. 306-313). Singapore: MERGA Inc.

Gervasoni, A., Parish, L., Hadden, T., Turkenburg, K., Bevan, K., Livesey, C., et al. (2011). Insights about children's understanding of 2-digit and 3-digit numbers. In J. Clark, B. Kissane, J. Mousley, T. Spencer, \& S. Thornton (Eds.), Mathematics: Traditions and [new] Practices. Proceedings of the 23rd Biennial Conference of The Australian Association of Mathematics Teachers and the 34th Annual Conference of the Mathematics Education Research Group of Australasia (Vol. 1, pp. 315-323). Alice Springs: MERGA/AAMT.

Gervasoni, A., Parish, L., Upton, C., Hadden, T., Turkenburg, K., Bevan, K., et al. (2010). Bridging the numeracy gap for students in low SES communities: The power of a whole school approach. In L. Sparrow, B. Kissane, \& C. Hurst (Eds.), Shaping the Future of Mathematics Education: Proceedings of the 33rd Annual Conference of the Mathematics Education Research Group of Australasia (pp. 202-209). Fremantle: MERGA.

Hart, B., Brinkman, S., \& Blackmore, S. (2003). How well are we raising our children in the North Metropolitan Region? Perth: Population health program, North Metropolitan Heath Service. 
Hill, H. C., Rowan, B., \& Ball, D. L. (2005). Effects of teachers' mathematical knowledge for teaching on student achievement. American Educational Research Journal, 42(2), 371-406.

Lindenskov, L., \& Weng, P. (2008). Specialundervisning I matematik-kan det ikke være lige meget? In S. Tetler \& S. Langager (Eds.), Specialunderisning $i$ skolen (pp. 211-230). Copenhagen: Gyldendal.

Magne, O. (2003). Literature on special educational needs in mathematics: A bibliography with some comments. Educational and psychological interactions (4th Ed.), 124. Malmö, Sweden: School of Education.

Scherer, P., Beswick, K., DeBlois, L. Healy, L., \& Optitz, E. (2016). Assistance of students with mathematical learning difficulties: How can research support practice? ZDM Mathematics Education, 48, 633-649. https://doi.org/10.1007/s11858-016-0800-1.

Smith, T. M., Cobb, P., Farran, D. C., Cordray, D. S., \& Munter, C. (2013). Evaluating math recovery: Assessing the causal impact of a diagnostic tutoring program on student achievement. American Educational Research Journal, 50(2), 397-428.

Open Access This chapter is licensed under the terms of the Creative Commons Attribution 4.0 International License (http://creativecommons.org/licenses/by/4.0/), which permits use, sharing, adaptation, distribution and reproduction in any medium or format, as long as you give appropriate credit to the original author(s) and the source, provide a link to the Creative Commons license and indicate if changes were made.

The images or other third party material in this chapter are included in the chapter's Creative Commons license, unless indicated otherwise in a credit line to the material. If material is not included in the chapter's Creative Commons license and your intended use is not permitted by statutory regulation or exceeds the permitted use, you will need to obtain permission directly from the copyright holder. 